Research Article

\title{
Multiresidue Method for Quantification of Sulfonamides and Trimethoprim in Tilapia Fillet by Liquid Chromatography Coupled to Quadrupole Time-of-Flight Mass Spectrometry Using QuEChERS for Sample Preparation
}

\author{
Kátia S. D. Nunes, ${ }^{1}$ Márcia R. Assalin, ${ }^{2}$ José H. Vallim, ${ }^{2}$ Claudio M. Jonsson, \\ Sonia C. N. Queiroz, ${ }^{2}$ and Felix G. R. Reyes $\varpi^{1}$ \\ ${ }^{1}$ Department of Food Science, School of Food Engineering, University of Campinas, Rua Monteiro Lobato 80, \\ 13083-862 Campinas, SP, Brazil \\ ${ }^{2}$ Embrapa Meio Ambiente, P.O. Box 69, 13820-000 Jaguariúna, SP, Brazil \\ Correspondence should be addressed to Felix G. R. Reyes; reyesfgr@gmail.com
}

Received 25 August 2017; Revised 14 December 2017; Accepted 31 December 2017; Published 1 March 2018

Academic Editor: Gauthier Eppe

Copyright (c) 2018 Kátia S. D. Nunes et al. This is an open access article distributed under the Creative Commons Attribution License, which permits unrestricted use, distribution, and reproduction in any medium, provided the original work is properly cited.

\begin{abstract}
A multiresidue method for detecting and quantifying sulfonamides (sulfapyridine, sulfamerazine, sulfathiazole, sulfamethazine, sulfadimethoxine, sulfamethoxazole, and sulfamethoxypyridazine) and trimethoprim in tilapia fillet (Oreochromis niloticus) using liquid chromatography coupled to mass spectrometry was developed and validated. The sample preparation was optimized using the QuEChERS approach. The chromatographic separation was performed using a C18 column and $0.1 \%$ formic acid in water and acetonitrile as the mobile phase in the isocratic elution mode. Method validation was performed based on the Commission Decision 2002/657/EC and Brazilian guideline. The validation parameters evaluated were linearity $(r \geq 0.99)$; limits of detection (LOD) and quantification (LOQ), $1 \mathrm{ng} \cdot \mathrm{g}^{-1}$ and $5 \mathrm{ng} \cdot \mathrm{g}^{-1}$, respectively; intraday and interdays precision (CV lower than $19.4 \%$ ). The

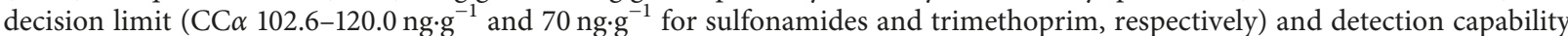
(CC $\beta$ 111.7-140.1 ng.g ${ }^{-1}$ and $89.9 \mathrm{ng} \cdot \mathrm{g}^{-1}$ for sulfonamides and trimethoprim, respectively) were determined. Analyses of tilapia fillet samples from fish exposed to sulfamethazine through feed (incurred samples) were conducted in order to evaluate the method. This new method was demonstrated to be fast, sensitive, and suitable for monitoring sulfonamides and trimethoprim in tilapia fillet in health surveillance programs, as well as to be used in pharmacokinetics and residue depletion studies.
\end{abstract}

\section{Introduction}

Brazil is one of the five largest veterinary markets in the world, and aquaculture, in particular fish farming, is the fastest growing sector of animal food production in the country $[1,2]$. In fish farming, antimicrobials, including sulfonamides, are used for the treatment of bacterial diseases. Sulfonamides (Figure 1) belong to an important group of synthetic antimicrobial agents that have been used in human and veterinary medicine for over 60 years. Recently, these drugs have been extensively employed in animals intended to produce food for human consumption since it is practically impossible to keep the production environment free of pathogenic organisms. Sulfonamides have become a useful tool for achieving high levels of productivity, thereby contributing to further growth, feed efficiency, and reduced mortality and morbidity [3]. However, sulfonamide residues are a major concern because of their potential risk to human health by development of bacterial resistance and adverse effects, such as allergic reactions, in hypersensitive people [4].

Trimethoprim (Figure 1) is a diaminopyrimidine antimicrobial agent, which is active against a wide range of Gram-positive and Gram-negative microorganisms including Escherichia coli and some Klebsiella, Proteus, 
<smiles>Nc1ccc(S(=O)(=O)Nc2ccccn2)cc1</smiles><smiles>COc1ccc(NS(=O)(=O)c2ccc(N)cc2)nn1</smiles><smiles>Cc1cc(C)nc(NS(=O)(=O)c2ccc(N)cc2)n1</smiles><smiles>COc1cc(NS(=O)(=O)c2ccc(N)cc2)nc(OC)n1</smiles><smiles>Cc1ccnc(NS(=O)(=O)c2ccc(N)cc2)n1</smiles><smiles>Nc1ccc(S(=O)(=O)Nc2nccs2)cc1</smiles><smiles>Cc1cc(NS(=O)(=O)c2ccc(N)cc2)no1</smiles><smiles>COc1cc(Cc2cnc(N)nc2N)cc(OC)c1OC</smiles>

Figure 1: Chemical structures of the sulfonamides and trimethoprim.

and Staphylococcus species. In veterinary medicine, it is often used in combination with a sulfonamide to increase the antimicrobial activity of the sulfonamides but is excreted faster. Consequently, if no residues of sulfonamide are detectable, no residues of trimethoprim would be expected. Trimethoprim is of low acute mammalian toxicity, and there is no evidence for the potentiation of acute toxicity when it is administered in combination with a sulfonamide [5].

At its 40th session, the Codex Alimentarius Commission reported a maximum residue limit (MRL) value for sulfadimidine (sulfamethazine) of $100 \mu \mathrm{g} \cdot \mathrm{kg}^{-1}$ in muscle, for species not specified [6]. According to the European Commission Regulation (EU) No. 37/2010 [7], for the muscle of fin fish, the MRL value for individual sulfonamides, or the combined total residues of all substances belonging to the sulfonamide group, is $100 \mu \mathrm{g} \cdot \mathrm{kg}^{-1}$. In relation to trimethoprim, the MRL value is $50 \mu \mathrm{g} \cdot \mathrm{kg}^{-1}$. The MRL value relates to the muscle and skin in natural proportions. In Brazil, the use of sulfonamides in farm-raised fish is not permitted (it does not appear in the legislative framework) and, therefore, its use is considered out of label (prohibited substance). However, for monitoring purposes (and taking actions), the Brazilian National Plan for Control of Residues and Contaminants (PNCRC/Fish) establishes a reference limit of $100 \mu \mathrm{g} \cdot \mathrm{kg}^{-1}$ for the residue of the individual sulfonamides (sulfachlorpyridazine, sulfadoxine, sulfamerazine, sulfadiazine, sulfamethoxazole, sulfathiazole, sulfamethazine, sulfaquinoxaline, and sulfadimethoxine) or the sum of them. Trimethoprim is not considered under the PNCRC/Fish sampling plan [8].

Studies on the determination of antimicrobial residues in foods of animal origin began in Belgium, the Netherlands, and Luxembourg in the late 1960s and early 1970s. In most European countries, research on residues and their application in inspection of slaughtered animals started later [9]. In relation to the sample preparation step, strategies such as salting out liquid-liquid extraction [10], solid-liquid extraction [11], and microscale matrix solid-phase dispersion [12] 
have been employed to perform the extraction and cleanup of sulfonamides from fish and other biological matrices. More recently, Ziarrusta et al. [13] used focused ultrasound solid-liquid extraction (FUSLE) for extraction of fluoroquinolones from fish tissues. The FUSLE method improves the extraction yield of target analytes (organic compounds), quantitatively, from biota samples. Regarding the systems of separation and detection, the high performance liquid chromatography-tandem mass spectrometry (HPLC-MS/MS) is an analytical technique that has been used in the determination of veterinary drug residues. In this regard, a few sulfonamide multiresidue methods in food matrices have been described in the literature by this technique $[14,15]$. For instance, Abdallah et al. [16] determined sulfonamide residues in sheep, pork, beef, chicken, and dromedary, Nebot et al. [17] in bovine milk, Tsai et al. [18] in different fish species, and Jansomboon et al. [19] in Pangasius catfish. Alternatively, a time-of-flight (TOF) mass spectrometer provides high sensitivity and accurate mass measurements $(0.005 \mathrm{Da})$, enabling the detection of low concentrations $\left(\mathrm{ng}^{-\mathrm{g}^{-1}}\right)$ of residues and contaminants in highly complex food matrices $[15,20]$. Nevertheless, to our knowledge, there is no reported multiresidue method for the combined quantification of sulfonamides and trimethoprim in tilapia fillet using liquid chromatography coupled to quadrupole time-of-flight mass spectrometry (LC-QTOF/MS).

The aim of this study was to develop and validate a rapid, simple (without the need of solid-phase extraction (SPE) cartridges or similar materials), and reliable multiresidue method for the identification and quantification of sulfonamides and trimethoprim in tilapia fillets (Oreochromis niloticus) by LC-QTOF/MS, to be suitable for application in monitoring programmes as well as in pharmacokinetic and residue depletion studies. The sample preparation involved the QuEChERS (Quick, Easy, Cheap, Effective, Rugged, and Safe) approach as described by Lehotay et al. [21]. The validation was conducted in-house based on the Commission Decision 2002/657/EC [22] and Brazilian guideline [23]. To evaluate the precision of the method, analysis of tilapia fillet samples from fish exposed to sulfamethazine through feed (incurred samples) was also conducted.

\section{Materials and Methods}

2.1. Chemicals and Reagents. The sulfonamide analytical standards (sulfathiazole (STZ), sulfamethoxazole (SMX), sulfamerazine (SMR), sulfamethoxypyridazine (SMPD), sulfadimethoxine (SDMX), sulfapyridine (SP), sulfamethazine (SMZ)), and trimethoprim (TMP) were purchased from Sigma-Aldrich Company Ltd. (St. Louis, MO, USA). All analytical standards had a purity greater than 99.0\%. Primary secondary amine (PSA) was obtained from United Chemical Technologies, Inc. (UCT Inc., Bristol, PA, USA), and formic acid (98\%) was purchased from Sigma-Aldrich Company Ltd. (St. Louis, MO, USA). Anhydrous magnesium sulfate was supplied by J.T. Baker (Center Valley, PA, USA) and sodium acetate trihydrate from Spectrum Chemical Mfg., Corp. (New Brunswick, NJ, USA). Methanol $(\mathrm{MeOH})$ and acetonitrile $(\mathrm{ACN})$ were obtained from
Honeywell Burdick \& Jackson (Muskegon, MI, USA) and J.T. Baker (Center Valley, PA, US), respectively. All solvents were of HPLC grade, and all reagents were of analytical grade. Ultra-pure deionized water was obtained from a MilliQ Plus water purification system (Millipore, Bedford, MA, USA). Filtration of the aqueous mobile phase was performed using polyvinylidene fluoride (PVDF) membranes, and polytetrafluoroethylene (PTFE) membranes were used for organic mobile-phase filtration, both with $0.22 \mu \mathrm{m}$ pore size obtained from Millipore (Bedford, MA, USA).

2.2. Instrumentation. The identification and quantitation of sulfonamides and trimethoprim was carried out using an UPLC-Q-TOF system comprising an Acquity UPLC system coupled to a hybrid quadrupole orthogonal time-of-flight (Q-TOF) mass spectrometer (SYNAPT HDMS Q-TOF mass spectrometer) with electrospray source ionization (ESI) in positive mode. The software of acquisition control and data treatment was the MassLynx version 4.1 (Waters Corp., Milford, MA, USA). For sample preparation, the following equipment were used: semianalytical balance (Tecnal; Boulder, CO, USA); analytical balance (Scientech, SA 210; Boulder, CO, USA); tubes stirring vortex type (IKA model MS1 Minishaker, $2700 \mathrm{rpm}$; Wilmington, DE, USA); refrigerated centrifuge (Thermo Scientific model Heraeus Multifuge 3 L-R; Madison, WI, USA); ultrasonic bath (Elma model Transsonic 660/H; Singen, Baden-Württemberg, Germany); Waring Commercial Blender, model 33BL79 (New Hartford, CT, USA); and Ultra-Turrax IKA, model TP $10 \mathrm{~N}$ (Wilmington, DE, USA).

2.3. Solution Preparation. Standard stock solutions of SP, STZ, SMZ, SDMX, SMX, SMPD, SMR, and TMP were prepared in acetonitrile at $1000 \mu \mathrm{g} \cdot \mathrm{mL}^{-1}$, stored in $10 \mathrm{~mL}$ bottles, and kept at $-20^{\circ} \mathrm{C}$. These solutions were used for a maximum period of 1 month. The intermediate standard solutions were prepared daily by dilution of stock solutions in an appropriate buffer solution.

2.4. Blank and Incurred Fish Samples. The blank samples of tilapia (Oreochromis niloticus) with no detectable analyte concentration used for the development and validation of the analytical method were provided by a local producer (Rio Doce fish farm, São João da Boa Vista, SP) with a guarantee that the fish were not exposed to the compounds that were the analytical focus of this work. Nonetheless, to ensure the viability of the blank samples, they were analysed, and the chromatograms did not show the presence of any interference at the retention time corresponding to the studied analytes. For validation of the analytical method, blank samples and incurred samples (truly contaminated samples) were used, that is, samples of fish exposed to SMZ through feed, obtained from an experiment conducted at Embrapa Environment, Jaguariuna, SP, Brazil, where tilapia were given SMZ at a dose level of $422 \mathrm{mg} \cdot \mathrm{kg}^{-1}$ body weight, for 11 consecutive days. The incurred samples used in this study were from fish slaughtered by thermal shock and immersion 
in an ice bath, $12 \mathrm{~h}$ after stopping medication. All samples were stored in a freezer $\left(-20^{\circ} \mathrm{C}\right)$ until analysis [24]. The experiment with fish to obtain the incurred samples was approved by the Ethics Committee on Animal Experiments of Embrapa Environment (Protocol No. 001/2013) [25].

2.5. Sample Preparation by QuEChERS. Tilapia fillet samples were ground using a domestic food processor. Triturated samples $(2.5 \mathrm{~g})$ were weighed in a $50 \mathrm{~mL}$ polypropylene tube, and ACN $(5 \mathrm{~mL})$ was added and then homogenized using a Turrax for 30 seconds. The homogenized sample was then added of $5 \mathrm{~mL} \mathrm{ACN}$, the tubes were shaken vigorously by vortexing for $1 \mathrm{~min}$ and placed in an ultrasonic bath for $5 \mathrm{~min}$. Next, $2.0 \mathrm{~g}$ of anhydrous magnesium sulfate and $0.75 \mathrm{~g}$ of sodium acetate were added to the homogenized samples and vortexed for $1 \mathrm{~min}$ and centrifuged at $17,500 \times \mathrm{g}$ for $10 \mathrm{~min}$, at $5^{\circ} \mathrm{C}$. For sample cleanup, an aliquot of $5.0 \mathrm{~mL}$ of supernatant was volumetrically pipetted to another tube containing $150 \mathrm{mg}$ of PSA and $0.5 \mathrm{~g}$ of anhydrous magnesium sulfate. The tube was subsequently vortexed for 30 seconds and centrifuged at $17,500 \times \mathrm{g}$ again for $5 \mathrm{~min}$, at $5^{\circ} \mathrm{C}$. A $2.0 \mathrm{~mL}$ aliquot of the supernatant was pipetted and transferred to another tube, and the solvent was completely evaporated under nitrogen stream, in an ice bath, to avoid losses of the analytes. Next, the residue was suspended in $0.5 \mathrm{~mL}$ of the mobile phase (ACN : $0.1 \%$ aqueous formic acid, $95: 5 \mathrm{v} / \mathrm{v}$ ). To facilitate the dissolution of analytes, the tubes were placed in ultrasonic bath for $5 \mathrm{~min}$. Finally, the resulting extracts were filtered through a cellulose filter unit $(0.22 \mu \mathrm{m}$ pore size $)$ directly into the vial and injected in the LC-QTOF/MS system. A schematic representation of the sample preparation procedure is shown in Figure 2.

2.6. UPLC-QTOF/MS Conditions. The chromatographic separation was performed on a reversed-phase analytical column Poroshell EC-120 C18 $(50 \mathrm{~mm} \times 2.1 \mathrm{~mm}, 2.7 \mu \mathrm{m})$, supplied by Agilent Technologies (Santa Clara, CA, USA) preceded by a similar precolumn $(30 \mathrm{~mm} \times 2.1 \mathrm{~mm}, 2.7 \mu \mathrm{m})$. The chromatographic separation was performed at $25^{\circ} \mathrm{C}$. The mobile phase was composed of (A) $\mathrm{H}_{2} \mathrm{O}$ : acetonitrile : formic acid $(95: 5: 0.1 \%, \mathrm{v} / \mathrm{v} / \mathrm{v})$ and $(\mathrm{B}) \mathrm{H}_{2} \mathrm{O}:$ acetonitrile : formic acid $(5: 95: 0.1 \%, \mathrm{v} / \mathrm{v} / \mathrm{v})$, and the isocratic elution mode was used with $70 \%(\mathrm{~A})$ and $30 \%(\mathrm{~B})$. The flow rate was $0.2 \mathrm{~mL} \cdot \mathrm{min}^{-1}$ with a run time of $4 \mathrm{~min}$ and injection volume of $5 \mu \mathrm{L}$.

The following ionization conditions were established for the ESI-QTOF/MS system: positive ionization mode, capillary voltage: $2.5 \mathrm{kV}$, detector voltage: $1.850 \mathrm{kV}$, sample cone voltage: $20.0 \mathrm{~V}$, extraction cone voltage: $2.0 \mathrm{~V}$, source temperature: $100^{\circ} \mathrm{C}$, desolvation gas temperature: $300^{\circ} \mathrm{C}$, nitrogen gas flow in the cone: $50 \mathrm{~L} \cdot \mathrm{h}^{-1}$, and desolvation flow: $400 \mathrm{~L} \cdot \mathrm{h}^{-1}$. The molecules of interest were quantified by monitoring the signal related to the protonated molecular ion $\mathrm{m} / z\left(\mathrm{M}+\mathrm{H}^{+}\right)$. The sulfonamide and trimethoprim identity was confirmed by obtaining the accurate mass of the protonated molecular ion, as well as by the consideration of fragment ions in order to obtain the identification points (IPs) according to Commission Decision 2002/657/EC [22] (Table 1).

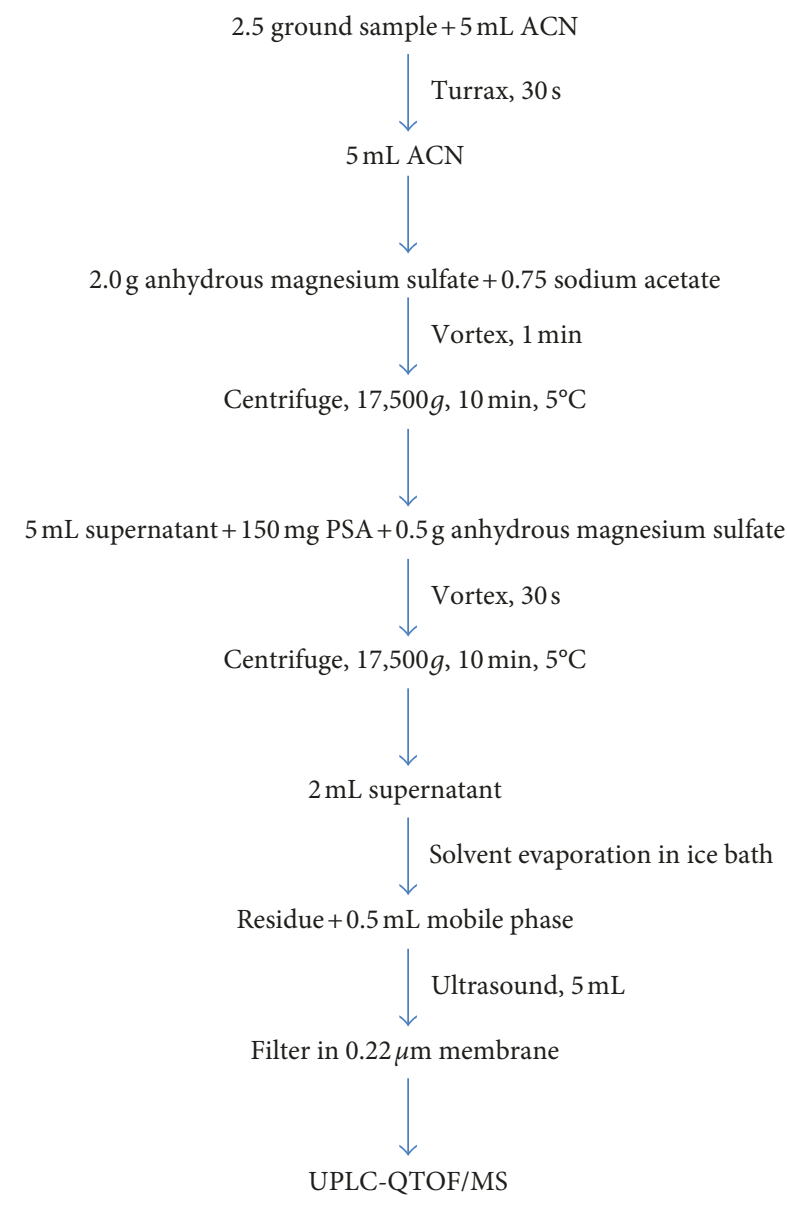

FIgURE 2: Schematic representation of the sample preparation procedure.

2.7. Validation Parameters. The purpose of this step was to establish the performance parameters and the minimum requirements of acceptance that must be satisfied such that the analytical method presented in this study is considered validated. The recommendations of the European Community [22] and the Guide to Analytical Methods Validation of the Brazilian Ministry of Agriculture, Livestock, and Supply [23] were used as reference to perform the method validation.

After optimization of the preparation procedure (extraction and cleanup), the validation of the analytical method was performed. The following validation parameters were evaluated: selectivity; linearity, sensitivity, and matrix effect; precision (intra- and interday); accuracy; and decision limit $(\mathrm{CC} \alpha)$ and detection capability $(\mathrm{CC} \beta)$. The limit of detection (LOD) and limit of quantification (LOQ) were also assessed to evaluate the potential use of the analytical method in pharmacokinetic and residue depletion studies where lower LOD and LOQ are required. Selectivity of the method was evaluated by comparing the chromatograms obtained from blank samples $(n=10)$ and the samples spiked with sulfonamides and trimethoprim standard solutions $(n=10)$. The chromatograms were evaluated for the presence of the analytical signal at the same retention time observed for the mass-to-charge ratio $(\mathrm{m} / \mathrm{z})$ of the analytes of interest. 
TABLE 1: Elemental composition, retention time, the $\mathrm{m} / \mathrm{z}$ experimental (precursors and fragment) ions, and mass error determined in standard solution for the studied analytes.

\begin{tabular}{lcccccc}
\hline Compound & $\begin{array}{c}\text { Molecular } \\
\text { formula }\end{array}$ & $\begin{array}{c}\text { Retention time } \\
(\mathrm{min})\end{array}$ & $\begin{array}{c}\text { Monoisotopic } \\
\text { mass (Da) }\end{array}$ & $\begin{array}{c}m / z \text { experimental } \\
{[\mathrm{M}+\mathrm{H}]^{+}(\mathrm{Da})}\end{array}$ & $\begin{array}{c}\text { Mass error } \\
(\mathrm{ppm})\end{array}$ & $\begin{array}{c}m / z \text { experimental } \\
\text { fragment ion }(\mathrm{Da})\end{array}$ \\
\hline Trimethoprim & $\mathrm{C}_{14} \mathrm{H}_{18} \mathrm{~N}_{4} \mathrm{O}_{3}$ & 0.83 & 290.1379 & 291.1460 & 1.0 & 123.0592 \\
Sulfapyridine & $\mathrm{C}_{11} \mathrm{H}_{11} \mathrm{~N}_{3} \mathrm{O}_{2} \mathrm{~S}$ & 1.08 & 249.0572 & 250.0650 & 0.0 & 156.0128 \\
Sulfamerazine & $\mathrm{C}_{11} \mathrm{H}_{12} \mathrm{~N}_{4} \mathrm{O}_{2} \mathrm{~S}$ & 1.18 & 264.0681 & 265.0760 & 0.4 & 108.0483 \\
Sulfathiazole & $\mathrm{C}_{9} \mathrm{H}_{9} \mathrm{~N}_{3} \mathrm{O}_{2} \mathrm{~S}_{2}$ & 0.99 & 255.0136 & 256.0210 & 1.6 & 1.4 \\
Sulfamethazine & $\mathrm{C}_{12} \mathrm{H}_{14} \mathrm{~N}_{4} \mathrm{O}_{2} \mathrm{~S}$ & 1.25 & 278.0837 & 279.0920 & 1.0127 \\
Sulfadimethoxine & $\mathrm{C}_{12} \mathrm{H}_{14} \mathrm{~N}_{4} \mathrm{O}_{4} \mathrm{~S}$ & 2.19 & 310.0736 & 311.0810 & 1.3 & 156.0475 \\
Sulfamethoxazole & $\mathrm{C}_{10} \mathrm{H}_{11} \mathrm{~N}_{3} \mathrm{O}_{3} \mathrm{~S}$ & 1.81 & 253.0521 & 254.0600 & 0.4 & 156.0124 \\
Sulfamethoxypyridazine & $\mathrm{C}_{11} \mathrm{H}_{12} \mathrm{~N}_{4} \mathrm{O}_{3} \mathrm{~S}$ & 1.44 & 280.0630 & 281.0710 & 0.7 & 156.0125 \\
\hline
\end{tabular}

Linearity was established from analytical curves obtained by duplicate analysis of blank samples spiked with trimethoprim and sulfonamides in the following concentra-

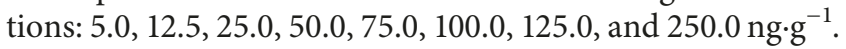
The results were analysed by the method of least squares , and the linearity was expressed through the coefficient of determination $\left(R^{2}\right)$ which was adopted as $R^{2} \geq 0.99$, as recommended by the Brazilian validation guide [23]. The matrix effect was evaluated by comparing three different concentrations $\left(12.5,50.0\right.$, and $\left.100.0 \mathrm{ng} \cdot \mathrm{g}^{-1}\right)$ of sulfonamides and trimethoprim, prepared in solvent and fortified extracts. The evaluation was done by comparing the area of the analytical signal in solvent with the area of analyte in the fortified extracts. Accuracy was evaluated by recovery tests of the spiked blank matrix at three concentration levels (10.0, 20.0 , and $40.0 \mathrm{ng} \cdot \mathrm{g}^{-1}$ ) with five replicates of each spiked level, during 3 days. The results were expressed as mean values $(n=15)$ of percentage of recoveries. The coefficient of variation $(\mathrm{CV} \%)$ is also reported.

The precision of the method was determined in two steps: intraday precision (repeatability) and interdays precision (intermediate precision). Repeatability was expressed as the $\mathrm{CV} \%$ of the results obtained with five replicates at three different concentrations (10.0, 20.0, and $40.0 \mathrm{ng} \cdot \mathrm{g}^{-1}$ ) analysed on the same day by the same analyst. The intermediate precision was expressed by CV\% of the results of three different concentrations with five replicates of each concentration on three different days by the same analyst.

The calculation of the decision limit $(\mathrm{CC} \alpha)$ and the detection capability $(\mathrm{CC} \beta)$ was based on the Commission Decision 2002/657/EC [22]. The decision limit is defined as the lowest concentration level at which the method can discriminate with a statistical certainty of $1-\alpha$ if the analyte is present. For substances with an MRL, the value of $\alpha$ is considered to be $5 \%$. The calculation was performed by analysing 20 blank samples fortified with the analyte at the MRL level. The concentration of the MRL plus 1.64 times the standard deviation corresponds to the $\operatorname{CC} \alpha(\alpha=5 \%)$. The detection capability $(\mathrm{CC} \beta)$ is the lowest amount of the substance that can be detected, identified, and/or quantified in a sample with an acceptable error probability $(\beta)$. For substances with an MRL, the determination of CC $\beta$ can be accomplished by the analysis of 20 blank samples fortified with the analyte in the decision limit $(\mathrm{CC} \alpha)$. The value of
CC $\alpha$ plus 1, 64 times the standard deviation, corresponds to the $\operatorname{CC} \beta(\beta=5 \%)$.

For each sulfonamide and trimethoprim, the LOD and LOQ were established by analysing the fortified matrix with standard solution of the analytes. LOD was determined based on signal-to-noise approach. Thus, LOD was expressed as the lowest concentration with a signal equal to three times the signal-to-noise ratio. The LOQ was taken as the first level of the analytical curve, which was measured with acceptable precision $(\mathrm{CV} \leq 20 \%)[26]$.

\section{Results and Discussion}

The representative sulfonamide veterinary drugs were chosen based on a study of their use in fish farming around the world, those monitored by the Brazilian National Plan for Control of Residues and Contaminants (PNCRC/Fish) of the Brazilian Ministry of Agriculture, Livestock, and Food Supply and those used for other animal species that could potentially be illegally employed in fish farming. Thus, sulfamethazine, sulfathiazole, sulfadimethoxine, sulfamerazine, sulfamethoxazole (monitored by the PNCRC/Fish [8]), sulfapyridine, sulfamethoxypyridazine, and trimethoprim (regulated for veterinary use [7], although not regulated for use in fish farming in Brazil) were selected. The maximum residue limit (MRL) adopted for all the sulfonamides (individual or the combined total residues) was $100 \mu \mathrm{g} \cdot \mathrm{kg}^{-1}$, and $50 \mu \mathrm{g} \cdot \mathrm{kg}^{-1}$ for trimethoprim [7].

3.1. Sample Preparation Based on QuEChERS. Dispersive solid-phase extraction (d-SPE) technique and QuEChERS have been previously used for the determination of veterinary drug residues in animal fluids and tissues [16, 27, 28], but not for the concomitant determination of sulfonamides and trimethoprim in fish fillet. It is well known that the step of sample preparation (extraction of analytes and cleanup of the extract) is crucial. This approach can influence the magnitude of the matrix effect, depending on the amount of endogenous substances from which it is coextracted. Acetonitrile has been widely used in the extraction of analytes from complex matrices as it extracts analytes with few interfering compounds (e.g., low amount of lipophilic coextractives from the sample) and further promotes the precipitation of proteins. This is necessary because the lower 
the quantity of interfering content present in the extract, the less matrix effect is observed, which leads to a better quality analysis [29].

Kruve et al. [30] reported the minimizing matrix effect in LC-ESI-MS analysis by using extrapolative dilution. It was demonstrated by several tests using QuEChERS sample preparation procedure that the use of a greater volume of acetonitrile for analyte extraction of complex matrices tends to reduce the matrix effect, possibly eliminating the matrix effect if a suitable dilution is achieved. It should be mentioned that although LC-ESI-QTOF/MS technique is very selective, possible interference caused by matrix substances can lead to suppression or an increase in the ionization of the analytes of interest [31]. Thus, this study explores the extraction of sulfonamides and trimethoprim by using QuEChERS procedure making use of acetonitrile as the extracting solvent and extrapolative dilution.

Preliminary studies have shown that for the quantification of sulfonamides and trimethoprim in tilapia fillet using the proportion of acetonitrile : sample $4: 1$ (v/w) showed the best results with fewer coextracts, thus decreasing the presence of interfering compounds. It is noteworthy that although the amount of sample used in this study was four times lower than that used by Lehotay et al. [21], it was possible to achieve an LOQ of $5 \mathrm{ng} \cdot \mathrm{g}^{-1}$ for all analytes, consequently to the LC-ESI-QTOF/MS system used. Literature data show that the LOQ for SDZ was $36 \mathrm{ng} \cdot \mathrm{g}^{-1}$, using $5 \mathrm{~g}$ of the sample [32]. Stubbings and Bigwood [33] showed an LOQ for SP, STZ, SMZ, SDMX, SMX, and SMR of $50 \mathrm{ng} \cdot \mathrm{g}^{-1}$, also using $5 \mathrm{~g}$ of the sample.

The addition of salts to promote the salting out effect has been shown to enhance the optimization of the analyte recovery percentages in multiresidue methods since it increases the solubility of these molecules in the organic phase $[34,35]$. In the QuEChERS approach reported by Lehotay et al. [21], $6 \mathrm{~g}$ of anhydrous magnesium sulfate and $2.5 \mathrm{~g}$ of sodium acetate trihydrate were used. In the present method for extracting sulfonamides and trimethoprim from tilapia fillet, $2 \mathrm{~g}$ of anhydrous magnesium sulfate and $0.75 \mathrm{~g}$ of sodium acetate trihydrate were employed. At the cleanup step, PSA and/or C18 were used. Since no significant variation was observed between them in relation to recovery values, we opted for the use of PSA only. This finding may be observed because the fat content in tilapia fillet is low. There are studies in matrices that have considerably higher fat content in which the concomitant use of PSA and C18 is required for a better cleanup of the sample extract [33].

3.2. Identity Confirmation of Analytes. On the basis of Commission Decision 2002/657/EC [22], the identity confirmation of a substance is performed by a system of identification points (IPs). The mass accuracy of a highresolution mass spectrometer acquires 2 IPs for the precursor ion and 2.5 for each transition product. The resolution of mass spectrometer used in this study (SYNAPT HDMS Q-TOF) is more than 10,000, which fall within the criteria established by the guide as a high-resolution MS. Under the conditions selected, the protonated molecule and one
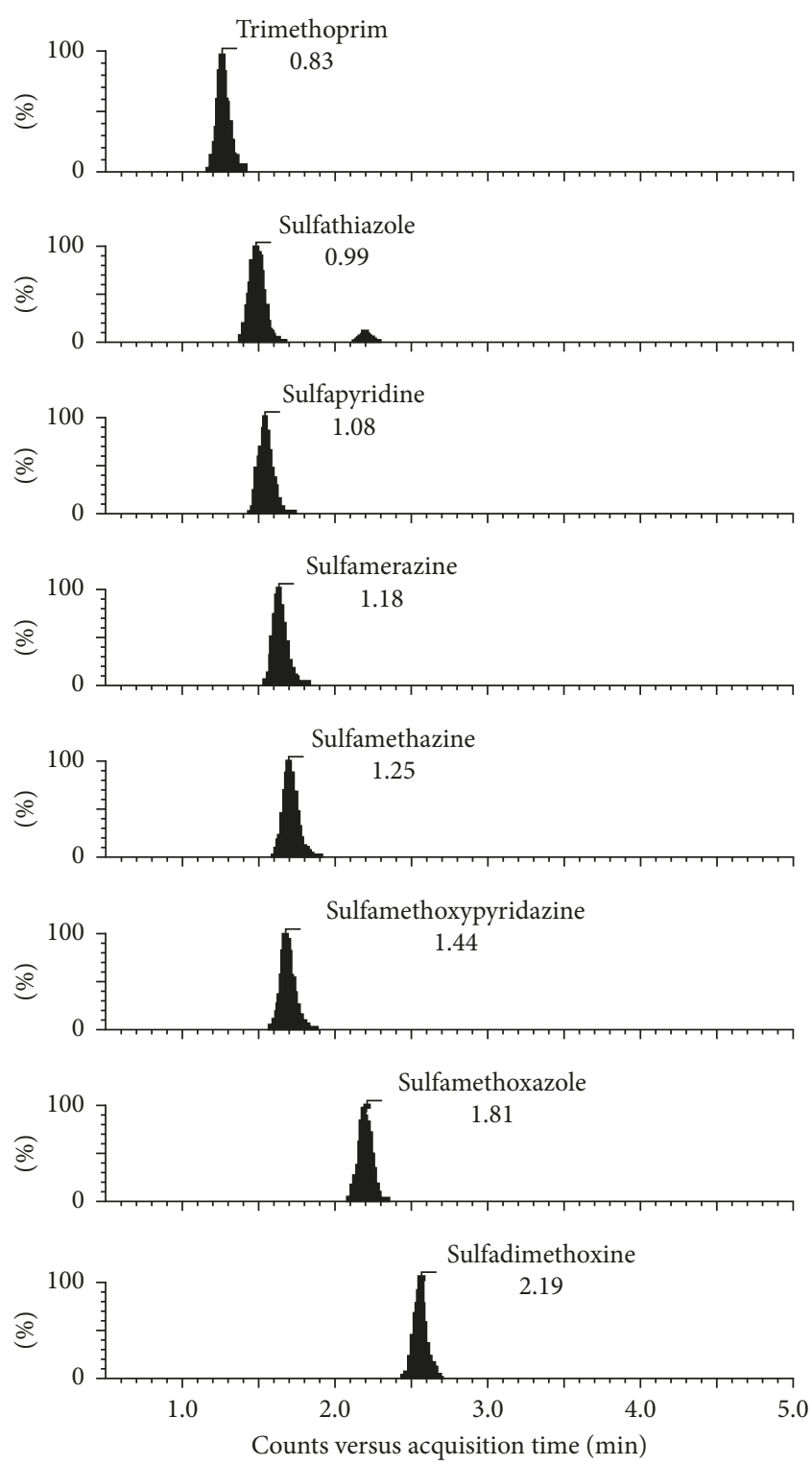

FIgURE 3: Extracted chromatograms of spiked samples with sulfonamides and trimethoprim at concentration of $50.0 \mathrm{ng} \cdot \mathrm{g}^{-1}$.

fragmented ion for each analyte could be monitored, thus reaching the requirements to confirm their identity in accordance with Commission Decision 2002/657/EC [22]. For the quantitative purpose, only the sulfonamides and trimethoprim molecular ions were monitored.

3.3. Analytical Method Validation. The method selectivity was evaluated by analysing ten samples free of analytes (blank samples) and comparing them to the chromatograms obtained from samples spiked with the sulfonamides and trimethoprim. Peaks for interfering compounds with the same retention times as the analytes of interest with the same $\mathrm{m} / \mathrm{z}$ were not observed. Therefore, the method performed is satisfactorily selective.

Figure 3 shows the chromatograms of each analyte studied. 
To study the linearity, sensitivity, and matrix effect, the analytical results at the following concentrations were compared: $5.0,12.5,25.0,50.0,75.0,100.0,125.0$, and $250.0 \mathrm{ng} \cdot \mathrm{mL}^{-1}$. Measurements were carried out for the analytes dissolved in the solvent, in the fortified extract, and in the fortified blank matrix (matrix-matched). The matrix effect, expressed as a percentage, was calculated from the division between the areas obtained for the analyte in solvent and in the fortified extract, at the same concentration level [36]. The highest matrix effect value observed was $18,98 \%$, which is below the maximum acceptable value by the validation guides (20\%) [22]. Thus, the matrix effect was considered irrelevant for this method. However, when comparing the analytical curves in extract with the curves in the fortified blank matrix, it was noted that the slope (angular coefficient) of the curve for the matrix-matched sample was much lower, indicating the loss of analytes (sulfonamides and trimethoprim) during sample preparation step (extraction and cleanup). Thus, for the present method a matrix-matched analytical curve must be employed.

Accuracy was evaluated from recovery tests (\%), as recommended by the Commission Decision 2002/657/EC when no certified reference material (CRM) is available [22]. The experiment was carried out through the recovery test of the spiked samples at 3 levels $\left(10.0,20.0\right.$, and $\left.40.0 \mathrm{ng} \cdot \mathrm{g}^{-1}\right)$, evaluating each level using 5 independent replicates on 3 consecutive days. Analytes SP, SMR, and TMP had satisfactory recovery values (between 79.5 and 103.6\%), SMZ and SMPD showed intermediate recoveries (between 64.6 and 80.0), and STZ, SDMX and SMX exhibit lower recovery values (between 38.4 and 52.9) (Table 2). Low recovery values for sulfonamides have been reported. Won et al. [37] reached a recovery of $58.8 \%$ for SDMX after extraction of this molecule from marine products, such as common eel, blue crab, shrimp, and flatfish, among others. Sulfonamides' low recoveries have also been reported in other matrices. Summa et al. [38] report recoveries for SMX and SDM, extracted from eggs, around $60 \%$ and $55 \%$, respectively. A review dealing about the presence of sulfonamides in edible tissues reports recoveries of various sulfonamides ranging from 40 to $67 \%$ for honey, $45-85 \%$ for pork veal, and $57-63 \%$ for salmon muscle [39]. Although recovery values found for some sulfonamides were below the percentage established in the validation guide [22], the method has been shown to be precise (CV\% found is within the value specified in the validation guide), and the required LOQ was achieved, which leads us to consider that the method is suitable for the intended purpose. Nevertheless, this corroborates the need to use matrix-matched analytical curves for the quantification of the analytes in samples of unknown origin.

The precision of the method was determined through intraday precision (repeatability) and interdays (intermediate precision) at three spiked levels and was expressed as coefficient of variation (CV\%). The intraday and interdays precision were evaluated in the concentration levels at 10.0, 20.0, and $40.0 \mathrm{ng} \cdot \mathrm{g}^{-1}$, with 5 replicates at each level. Working in this concentration range, we can ensure the precision and accuracy since in the most dispersive points, the CV is $\leq 20 \%$. The repeatability (analysed on the same day and same equipment) and the interdays precision (intermediate precision) are shown in Table 3.

For compounds with concentration levels lower than

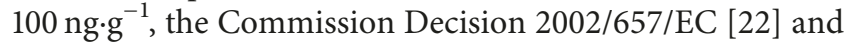
Brazilian validation guideline [23] recommend a maximum acceptable $\mathrm{CV} \leq 20 \%$. As shown in Table 3 , the validation parameters (intraday and interdays precision) meet the specifications recommended by both guides since they recommend a $\mathrm{CV} \leq 20 \%$.

The decision limit $(\mathrm{CC} \alpha)$ is a parameter that takes into account the precision of the method for establishing a critical reference level, from which we can conclude that a sample is classified as nonconforming with a probability of error of $5 \%$. An additional critical parameter, detection capability (CC $\beta)$, is calculated for use with nonconforming samples in order to confirm their concentration, and their identities are confirmed with an error probability of $5 \%(\beta=5 \%)$.

The decision limit $(\mathrm{CC} \alpha)$ and detection capability $(\mathrm{CC} \beta)$ values for each of the analyte studied are shown in Table 4. For sulfonamides, values varied from 102.6 to $120.0 \mu \mathrm{g} \cdot \mathrm{kg}^{-1}$ and from 111.7 to $140.1 \mu \mathrm{g} \cdot \mathrm{kg}^{-1}$ for $\mathrm{CC} \alpha$ and $\mathrm{CC} \beta$, respectively. For trimethoprim, those values were 70.0 and $89.9 \mu \mathrm{g} \cdot \mathrm{kg}^{-1}$, respectively. Thus, considering the MRL values of $100 \mu \mathrm{g} \cdot \mathrm{kg}^{-1}$ and $50 \mu \mathrm{g} \cdot \mathrm{kg}^{-1}$, respectively, for sulfonamides and trimethoprim, established by the regulatory framework of the European Union in fin fish [7], we can conclude that the method reported here is suitable for application in surveillance programmes of residues of sulfonamides and trimethoprim in fin fish muscle samples.

The evaluation of LOD and LOQ for the determination of sulfonamides and trimethoprim residues in tilapia fillet was performed using the matrix-matched analytical curve fortified with the analytes. The LOD and LOQ of the method were $1.0 \mathrm{ng} \cdot \mathrm{g}^{-1}$ and $5.0 \mathrm{ng} \cdot \mathrm{g}^{-1}$ for all sulfonamides and trimethoprim, respectively. The LOQ was validated by analyse of 10 replicates that showed a $C V \leq 20 \%$ for all of the analytes. This indicates that due to the low value of LOQ obtained, the method can be used by restrictive regulatory agencies of countries such as Japan [40], which, for the multiresidue method intended for quantification of veterinary drug residues in animal and fishery products, adopt for individual sulfonamides and trimethoprim a LOQ value of $10 \mathrm{ng} \cdot \mathrm{g}^{-1}$ and $20 \mathrm{ng} \cdot \mathrm{g}^{-1}$, respectively.

3.4. Analysis of Incurred Samples. To assess the method developed, analysis was performed on genuinely contaminated (incurred) fish samples obtained from an experiment in laboratory where the fishes were exposed to SMZ through the feed. This study was related to the effects of dietary exposure to SMZ on the haematological parameters and hepatic oxidative stress biomarkers in Nile tilapia [25]. The residue of SMZ in the muscle of 10 independent samples analysed in the same day was $1,062.9 \pm 53.2 \mathrm{ng} \cdot \mathrm{g}^{-1}$ (mean value \pm standard deviation), and the precision (CV\%) was 5.0\%. Due to the high concentration levels, the extract of the samples was diluted prior to injection to adjust the concentration to fit the range of the analytical curve. This corroborates the precision of the method and provides confidence that it is appropriate 
TABLE 2: Validation parameters of sulfonamides and trimethoprim.

\begin{tabular}{|c|c|c|c|c|c|c|c|c|}
\hline \multirow{2}{*}{ Validation parameters } & \multicolumn{8}{|c|}{ Sulfonamides and trimethoprim } \\
\hline & SP & STZ & SMZ & SDMX & SMX & SMPD & SMR & TMP \\
\hline Working range $\left(\mathrm{ng}^{-\mathrm{g}^{-1}}\right)$ & $5-250$ & $5-250$ & $5-250$ & $5-250$ & $5-250$ & $5-250$ & $5-250$ & $5-250$ \\
\hline Linearity $\left(R^{2}\right)$ & 0.9958 & 0.9914 & 0.9922 & 0.9992 & 0.9994 & 0.9935 & 0.9964 & 0.9984 \\
\hline Sensibility & 1174.07 & 633.811 & 2324.3 & 2670.56 & 1626.52 & 2057.08 & 1345.72 & 1588.92 \\
\hline \multicolumn{9}{|l|}{ Matrix effect (\%) } \\
\hline $12.5 \mathrm{ng} \cdot \mathrm{g}^{-1}$ & -18.98 & -2.07 & -11.19 & -3.58 & -5.22 & 9.57 & -3.68 & 9.65 \\
\hline $50{\mathrm{ng} \cdot \mathrm{g}^{-1}}^{-1}$ & 1.60 & 14.71 & 0.37 & -3.28 & 1.13 & -4.15 & 1.85 & -0.12 \\
\hline $100 \mathrm{ng} \cdot \mathrm{g}^{-1}$ & 0.13 & -7.02 & 0.46 & 1.61 & -1.77 & 3.74 & 0.79 & -0.03 \\
\hline \multicolumn{9}{|c|}{ Accuracy (\% recovery $(\mathrm{CV} \%))$} \\
\hline $10 \mathrm{ng} \cdot \mathrm{g}^{-1}$ & $83.9(14.4)$ & $52.9(19.2)$ & $69.1(19.4)$ & $49.6(17.8)$ & $45.4(11.9)$ & $80.0(9.4)$ & $79.5(15.4)$ & $92.0(13.2)$ \\
\hline $20 \mathrm{ng} \cdot \mathrm{g}^{-1}$ & $91.5(19.3)$ & $38.4(17.2)$ & $72.4(11.8)$ & $47.4(3.4)$ & $41.8(4.2)$ & $66.8(9.0)$ & $85.4(16.7)$ & $88.2(17.7)$ \\
\hline $40 \mathrm{ng} \cdot \mathrm{g}^{-1}$ & $103.6(19.0)$ & $41.3(18.6)$ & $68.0(19.1)$ & $51.1(4.5)$ & $43.5(10.0)$ & $64.6(5.5)$ & $81.2(15.0)$ & $91.5(16.2)$ \\
\hline LOD (ng.g ${ }^{-1}$ ) & 1.0 & 1.0 & 1.0 & 1.0 & 1.0 & 1.0 & 1.0 & 1.0 \\
\hline LOQ (ng.g $\left.{ }^{-1}\right)$ & 5.0 & 5.0 & 5.0 & 5.0 & 5.0 & 5.0 & 5.0 & 5.0 \\
\hline
\end{tabular}

SP, sulfapyridine; STZ, sulfathiazol; SMZ, sulfamethazine; SDMX, sulfadimethoxine; SMX, sulfamethoxazole; SMPD, sulfamethoxypyridazine; SMR, sulfamerazine; TMP, trimethoprim; LOD, limit of detection; LOQ, limit of quantitation; CV, coefficient of variation.

TABLE 3: Intraday and interdays precision of sulfonamides and trimethoprim.

\begin{tabular}{|c|c|c|c|c|c|c|c|c|}
\hline \multirow{2}{*}{ Validation parameters } & \multicolumn{8}{|c|}{ Sulfonamides and trimethoprim } \\
\hline & SP & STZ & SMZ & SDMX & SMX & SMPD & SMR & TMP \\
\hline \multicolumn{9}{|c|}{ Intraday precision (CV\%) } \\
\hline $10{\mathrm{ng} \cdot \mathrm{g}^{-1}}^{-1}$ & 12.8 & 11.7 & 11.6 & 7.7 & 6.4 & 7.1 & 11.3 & 8.3 \\
\hline $20 \mathrm{ng} \cdot \mathrm{g}^{-1}$ & 11.2 & 8.2 & 8.3 & 7.7 & 5.9 & 13.9 & 13.6 & 7.8 \\
\hline $40{\mathrm{ng} \cdot \mathrm{g}^{-1}}^{-1}$ & 12.9 & 14.9 & 15.0 & 12.3 & 7.9 & 6.1 & 14.5 & 10.6 \\
\hline \multicolumn{9}{|c|}{ Interdays precision (CV\%) } \\
\hline $10 \mathrm{ng} \cdot \mathrm{g}^{-1}$ & 14.4 & 19.2 & 19.4 & 17.8 & 11.9 & 9.4 & 15.4 & 13.2 \\
\hline $20 \mathrm{ng}^{-\mathrm{g}^{-1}}$ & 19.3 & 17.2 & 11.8 & 3.4 & 4.2 & 9.0 & 16.7 & 17.7 \\
\hline $40 \mathrm{ng} \cdot \mathrm{g}^{-1}$ & 19.0 & 18.6 & 19.1 & 4.5 & 10.0 & 5.5 & 15.0 & 16.2 \\
\hline
\end{tabular}

SP, sulfapyridine; STZ, sulfathiazol; SMZ, sulfamethazine; SDMX, sulfadimethoxine; SMX, sulfamethoxazole; SMPD, sulfamethoxypyridazine; SMR, sulfamerazine; TMP, trimethoprim; CV, coefficient of variation.

TABLE 4: CC $\alpha$ and $\operatorname{CC} \beta$ values for sulfonamides and trimethoprim in tilapia fillet.

\begin{tabular}{|c|c|c|c|c|c|c|c|c|}
\hline \multirow{2}{*}{ Validation parameters } & \multicolumn{8}{|c|}{ Sulfonamides ${ }^{\mathrm{a}}$ and trimethoprim ${ }^{\mathrm{b}}$} \\
\hline & SP & STZ & SMZ & SDMX & SMX & SMPD & SMR & TMP \\
\hline Limit of decision $(\mathrm{CC} \alpha)$, ng. $\mathrm{g}^{-1}$ & 119.8 & 110.9 & 114.0 & 102.6 & 102.9 & 105.9 & 120.0 & 70.0 \\
\hline Detection capability $(\mathrm{CC} \beta), \mathrm{ng}^{-\mathrm{g}^{-1}}$ & 139.7 & 121.7 & 122.0 & 117.1 & 111.7 & 118.2 & 140.1 & 89.9 \\
\hline
\end{tabular}

SP, sulfapyridine; STZ, sulfathiazole; SMZ, sulfamethazine; SDMX, sulfadimethoxine; SMX, sulfamethoxazole; SMPD, sulfamethoxypyridazine; SMR, sulfamerazine; TMP, trimethoprim. ${ }^{a}$ The MRL value adopted for the calculation of CC $\alpha$ and CC $\beta$ for all sulfonamides was $100 \mathrm{ng} \cdot \mathrm{g}^{-1}$ [6]. ${ }^{\mathrm{b}}$ The MRL value adopted for the calculation of CC $\alpha$ and $\operatorname{CC} \beta$ for TMP was $50 \mathrm{ng}^{-1}{ }^{-1}[6]$.

for the intended purpose and can be used by regulatory agencies in health surveillance programs, as well as in pharmacokinetics and residue depletion studies.

\section{Conclusions}

A multiresidue method for determination of sulfonamides STZ, SMX, SMR, SMPD, SDMX, SP, and SMZ and trimethoprim (TMP) in tilapia fillet was developed and validated. The analytes selected were those most frequently used worldwide in fish farming and those with the greatest potential for illegal use. QuEChERS approach with extrapolative dilution was shown to be a simple and inexpensive sample preparation process that can be easily used in routine analysis. Quantitation by liquid chromatographyquadrupole time-of-flight mass spectrometry (LC-ESIQTOF/MS) showed to be a selective and low detectability method. Thus, the method is suitable for application in 
monitoring programmes of residues of sulfonamides and trimethoprim in tilapia fillet, even by countries such as Japan that adopt low LOQ values for analytical methods to be used in food for determination of residues of substances such as veterinary drugs. Also, it was shown to be appropriate to be used in pharmacokinetic and residue depletion studies.

\section{Conflicts of Interest}

The authors declare that there are no conflicts of interest regarding the publication of this paper.

\section{Acknowledgments}

The authors gratefully acknowledge the financial support received from São Paulo Research Foundation-Agilent Technologies (FAPESP-Agilent, 2013/50452-5), the Brazilian Coordination for the Improvement of Higher Education Personnel (PROEX/CAPES, 3300301702P1), and the Brazilian National Council of Technological and Scientific Development $(\mathrm{CNPq})$. The authors also thank Dr. Patricia Aparecida de Campos Braga for her technical assistance in reviewing the manuscript.

\section{References}

[1] FAO, "Yearbook 2014 fishery and aquaculture statistics," 2016, http://www.fao.org/fishery/publications/yearbooks/en.

[2] MPA, "Ministério da pesca e aquicultura. Boletim estatístico da pesca e aquicultura Brasília,” 2011, http://www.icmbio.gov. br/cepsul/images/stories/biblioteca/download/estatistica/est_ 2011_bol_bra.pdf.

[3] C. K. V. Nonaka, A. M. G. Oliveira, C. R. Paiva et al., "Occurrence of antimicrobial residues in Brazilian food animals in 2008 and 2009," Food Additives and Contaminants, vol. 29, no. 4, pp. 526-534, 2012.

[4] I. R. Pecorelli, L. Bibi, R. Fiorino, and R. Galarini, "Validation of a confirmatory method for determination of sulphonamides in muscle according to the European Union regulation 2002/657/EC," Journal of Chromatography A, vol. 1032, no. 1-2, pp. 23-29, 2004.

[5] EMEA, "The European Agency for the evaluation of medicinal products. Committee for veterinary medicinal products. Trimethoprim summary report," 2009, http://www.ema.europa. eu/docs/en_GB/document_library/Maximum_Residue_Limits_-_ Report/2009/11/WC500015678.pdf.

[6] Codex Alimentarius, "Maximum residue limits (MRLs) and risk management recommendations (RMRs) for residues of veterinary drugs in foods. CAC/MRL 2-2017. Updated at the 40th session of the Codex Alimentarius Commission," 2017, http://www.fao.org/fao-who-codexalimentarius/codex-texts/ maximum-residue-limits/en/.

[7] EU, "Council regulation (EU) no. 37/2010 of 22 December 2009, on pharmacologically active substances and their classification regarding maximum residue limits in foodstuffs of animal origin," Official Journal of the European Union, L 15/1, 2010, https:// ec.europa.eu/health/sites/health/files/files/eudralex/vol-5/reg 2010_37/reg_2010_37_en.pdf.

[8] MAPA, "Ministério da agricultura, pecuária e abastecimento. National plan for residues and contaminants control PNCRC. Instrução normativa no. 09, de 21 de fevereiro de," 2017, http://www.agricultura.gov.br/assuntos/inspecao/produtos- animal/plano-de-nacional-de-controle-de-residuos-e-contaminantes/ documentos-da-pncrc/pncrc-2017.pdf.

[9] H. F. de Bradander, H. Noppe, K. Verheyden et al., "Residue analysis: future trends from a historical perspective," Journal of Chromatography A, vol. 1216, no. 46, pp. 7964-7976, 2009.

[10] J. Liu, M. Jiang, G. Li, L. Xu, and M. Xie, "Miniaturized salting-out liquid-liquid extraction of sulfonamides from different matrices," Analytica Chimica Acta, vol. 679, no. 1-2, pp. 74-80, 2010.

[11] S. Borràs, R. Companyó, and J. Guiteras, "Analysis of sulfonamides in animal feeds by liquid chromatography with fluorescence detection," Journal of Agriculture and Food Chemistry, vol. 59, no. 10, pp. 5240-5247, 2011.

[12] Q. Shen, R. Jin, J. Xue, Y. Lu, and Z. Dai, "Analysis of trace levels of sulfonamides in fish tissue using micro-scale pipette tip-matrix solid-phase dispersion and fast liquid chromatography tandem mass spectrometry," Food Chemistry, vol. 194, pp. 508-515, 2016.

[13] H. Ziarrusta, N. Val, H. Dominguez et al., "Determination of fluoroquinolones in fish tissues, biological fluids, and environmental waters by liquid chromatography tandem mass spectrometry," Analytical and Bioanalytical Chemistry, vol. 409, no. 27, pp. 6359-6370, 2017.

[14] M. Piatkowska, P. Jedziniak, and J. Zmudzki, "Multiresidue method for the simultaneous determination of veterinary medicinal products, feed additives and illegal dyes in eggs using liquid chromatography-tandem mass spectrometry," Food Chemistry, vol. 197, pp. 571-580, 2016.

[15] O. Lacina, J. Urbanova, J. Poustka, and J. Hajslova, "Identification/quantification of multiple pesticide residues in food plants by ultra-high-performance liquid chromatographytime-of-flight mass spectrometry," Journal of Chromatography A, vol. 1217, no. 5, pp. 648-659, 2010.

[16] H. Abdallah, C. Arnaudguilhem, R. Lobinskib, and F. Jaber, "A multi-residue analysis of sulphonamides in edible animal tissues using QuEChERS extraction and HPLC-MS/MS," Analytical Methods, vol. 7, no. 4, pp. 1549-1557, 2015.

[17] C. Nebot, P. Regal, J. M. Miranda, C. Fente, and A. Cepeda, "Rapid method for quantification of nine sulfonamides in bovine milk using HPLC/MS/MS and without using SPE," Food Chemistry, vol. 141, no. 3, pp. 2294-2299, 2013.

[18] C. Tsai, C. Lin, and W. Wang, "Multi-residue determination of sulfonamide and quinolone residues in fish tissues by high performance liquid chromatography-tandem mass spectrometry (LC-MS/MS)," Journal of Food and Drug Analysis, vol. 20, pp. 674-680, 2012.

[19] W. Jansomboon, S. K. Boontanon, N. Boontanon, C. Polprasert, and C. T. Da, "Monitoring and determination of sulfonamide antibiotics (sulfamethoxydiazine, sulfamethazine, sulfamethoxazole and sulfadiazine) in imported Pangasius catfish products in Thailand using liquid chromatography coupled with tandem mass spectrometry," Food Chemistry, vol. 212, pp. 635-640, 2016.

[20] S. B. Turnipseed, S. B. Clark, J. M. Storey, and J. R. Carr, "Analysis of veterinary drug residues in frog legs and other aquaculture species using liquid chromatography quadrupole time-of-flight Mass Spectrometry," Journal of Agricultural and Food Chemistry, vol. 60, no. 18, pp. 4430-4439, 2012.

[21] S. J. Lehotay, K. Mastovska, A. R. Lightfield, and R. A. Gates, "Multi-Analyst, multi-matrix performance of the QuEChERS approach for pesticide residues in foods and feeds using HPLC/MS/MS analysis with different calibration techniques," Journal of AOAC International, vol. 93, pp. 355-367, 2010. 
[22] Commission Decision 2002/657/EC, "Implementing Council Directive 96/23/EC concerning the performance of analytical methods and the interpretation of results," Official Journal of the European Communities, L221/8, 2002.

[23] MAPA, "Ministério da agricultura, pecuária e abastecimento. Guia de validação e controle de qualidade analítica: fármacos em produtos para alimentação e medicamentos veterinários," 2011, https://bibliotecaquimicaufmg2010.files.wordpress.com/2012/ 02/guia-de-validac3a7c3a3o-e-controle-de-qualidade-analc3adtica. pdf.

[24] M. E. Dasenaki and N. S. Thomaidis, "Multi-residue determination of seventeen sulfonamides and five tetracyclines in fish tissue using a multistage LC-ESI-MS/MS approach based on advanced mass spectrometric Techniques," Analytica Chimica Acta, vol. 672, no. 1-2, pp. 93-102, 2010.

[25] F. G. Sampaio, M. L. Carra, C. M. Jonsson et al., "Effects of dietary exposure to Sulfamethazine on the hematological parameters and hepatic oxidative stress biomarkers in Nile tilapia (Oreochromis niloticus)," Bulletin of Environmental Contamination and Toxicology, vol. 97, no. 4, pp. 528-535, 2016.

[26] J. A. R. Paschoal, S. Rath, F. P. S. Airoldi, and F. G. R. Reyes, "Validação de métodos cromatográficos para a determinação de resíduos de medicamentos veterinários em alimentos," Química Nova, vol. 31, no. 5, pp. 1190-1198, 2008.

[27] A. L. Capriotti, C. Cavaliere, A. Lagana, S. Piovesana, and R. Samperi, "Recent trends in matrix solid-phase dispersion," Trends in Analytical Chemistry, vol. 43, pp. 53-66, 2013.

[28] J. C. Hashimoto, J. A. Paschoal, S. C. N. Queiroz, V. L. Ferracini, M. R. Assalin, and F. G. R. Reyes, "A simple method for the determination of malachite green and leucomalachite green residues in fish by a modified QuEChERS extraction and HPLC-MS/MS," Journal of AOAC International, vol. 95, no. 3, pp. 913-922, 2012.

[29] A. Kruve, A. Kunnapas, K. Herodes, and I. Leito, "Matrix effects in pesticide multiresidue analysis by liquid chromatographymass spectrometry," Journal of Chromatography A, vol. 1187, no. 1-2, pp. 58-66, 2008.

[30] A. Kruve, I. Leito, and K. Herodes, "Combating matrix effects in LC/ESI/MS: the extrapolative dilution approach," Analytica Chimica Acta, vol. 651, no. 1, pp. 75-80, 2009.

[31] S. C. N. Queiroz, V. L. Ferracini, and M. A. Rosa, "Multiresidue method validation for determination of pesticides in food using QuEChERS and UPLC-MS/MS," Quimica Nova, vol. 35, pp. 185-192, 2012.

[32] C. C. Pericás, A. Maquieira, R. Puchades, B. Company, and J. Miralles, "Multiresidue determination of antibiotics in aquaculture fish by HPLC-MS/MS," Aquaculture Research, vol. 41, pp. 217-225, 2010.

[33] G. Stubbings and T. Bigwood, "The development and validation of a multiclass liquid chromatography tandem mass spectrometry (LC-MS/MS) procedure for the determination of veterinary drug residues in animal tissue using a QuEChERS (quick, easy, cheap, effective, rugged and safe) approach," Analytica Chimica Acta, vol. 637, no. 1-2, pp. 68-78, 2009.

[34] K. Zhang, J. W. Wong, P. Yang et al., "Multiresidue pesticide analysis of agricultural commodities using acetonitrile saltout extraction, dispersive solid-phase sample clean-up, and high-performance liquid chromatography tandem mass spectrometry," Journal of Agricultural and Food Chemistry, vol. 59, no. 14, pp. 7636-7646, 2011.

[35] S. C. Nanita and N. L. T. Padivitage, "Ammonium chloride salting out extraction/cleanup for trace-level quantitative analysis in food and biological matrices by flow injection tandem mass spectrometry," Analytica Chimica Acta, vol. 768, pp. 1-11, 2013.

[36] S. P. Quesada, J. A. R. Paschoal, and F. G. Reyes, "A simple method for the determination of fluoroquinolone residues in tilapia (Oreochromis niloticus) and pacu (Piaractus mesopotamicus) employing LC-MS/MS QtoF," Food Additives and Contaminants A, vol. 30, no. 5, pp. 813-825, 2013.

[37] S. Y. Won, C. H. Lee, H. S. Chang, S. O. Kim, S. H. Lee, and D. S. Kim, "Monitoring of 14 sulfonamide antibiotic residues in marine products using HPLC-PDA and LC-MS/MS," Food Control, vol. 22, no. 7, pp. 1101-1107, 2011.

[38] S. Summa, S. L. Magro, A. Armentano, and M. Muscarella, "Development and validation of an HPLC/DAD method for the determination of 13 sulphonamides in eggs," Food Chemistry, vol. 187, pp. 477-484, 2015.

[39] S. Wang, H. Y. Zhang, L. Wang, Z. J. Duan, and I. Kennedy, "Analysis of sulphonamide residues in edible animal products: a review," Food Additives and Contaminants, vol. 23, no. 4, pp. 362-384, 2006

[40] JPL, "The Japanese positive list system for agricultural chemical residues in foods. MRLs of agricultural chemicals, feed additives and veterinary drugs in foods. Ministry of Health Labour and Welfare Japan,” 2006, http://www.ffcr.or. jp/zaidan/ffcrhome.nsf/pages/mrls-p/. 

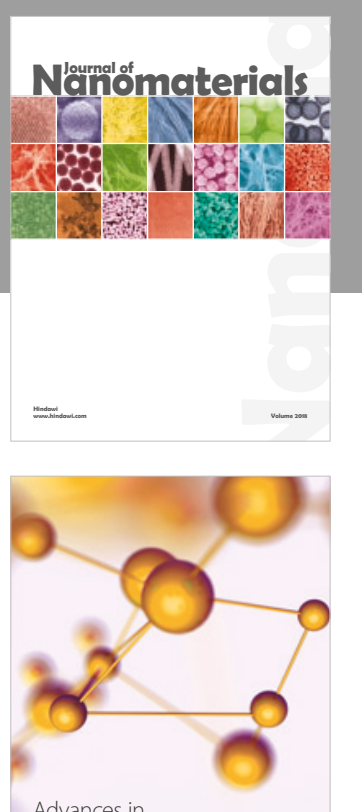

Physical Chemistry
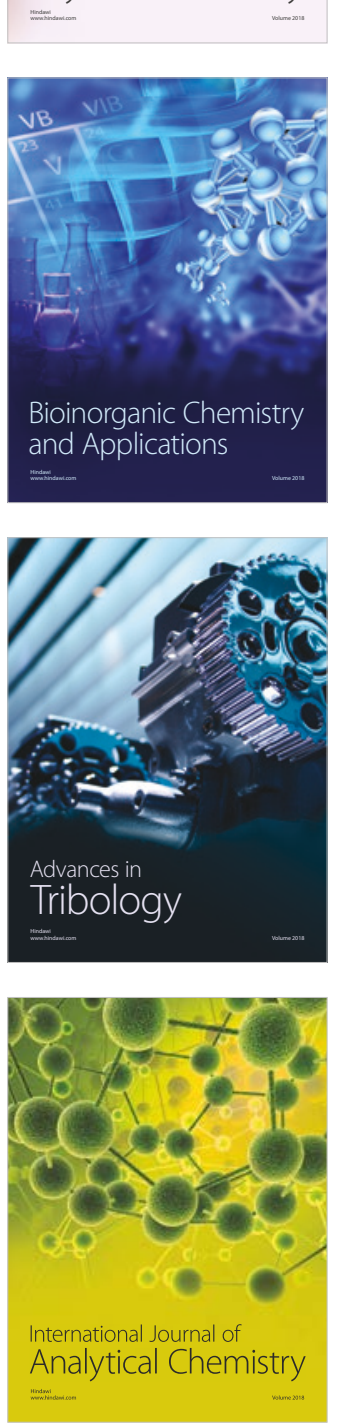

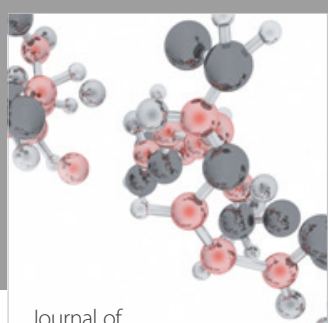

Analytical Methods

in Chemistry

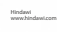

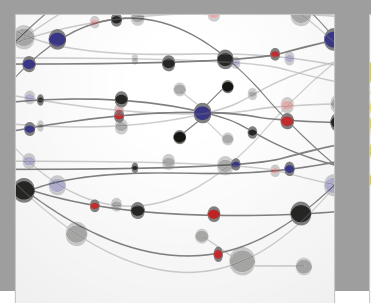

The Scientific World Journal

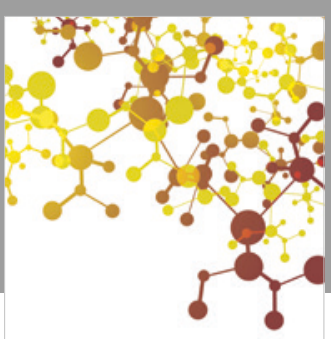

Journal of

Applied Chemistry
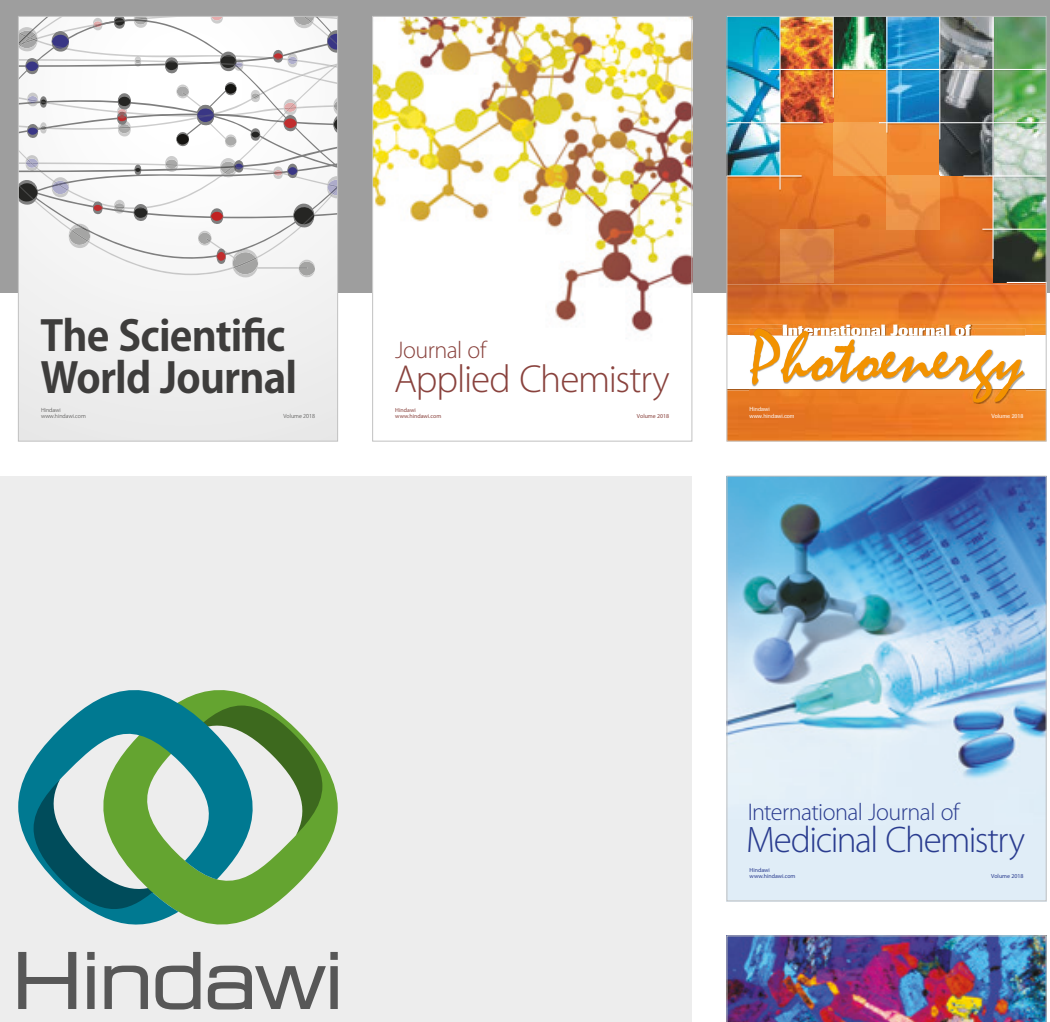

Submit your manuscripts at

www.hindawi.com
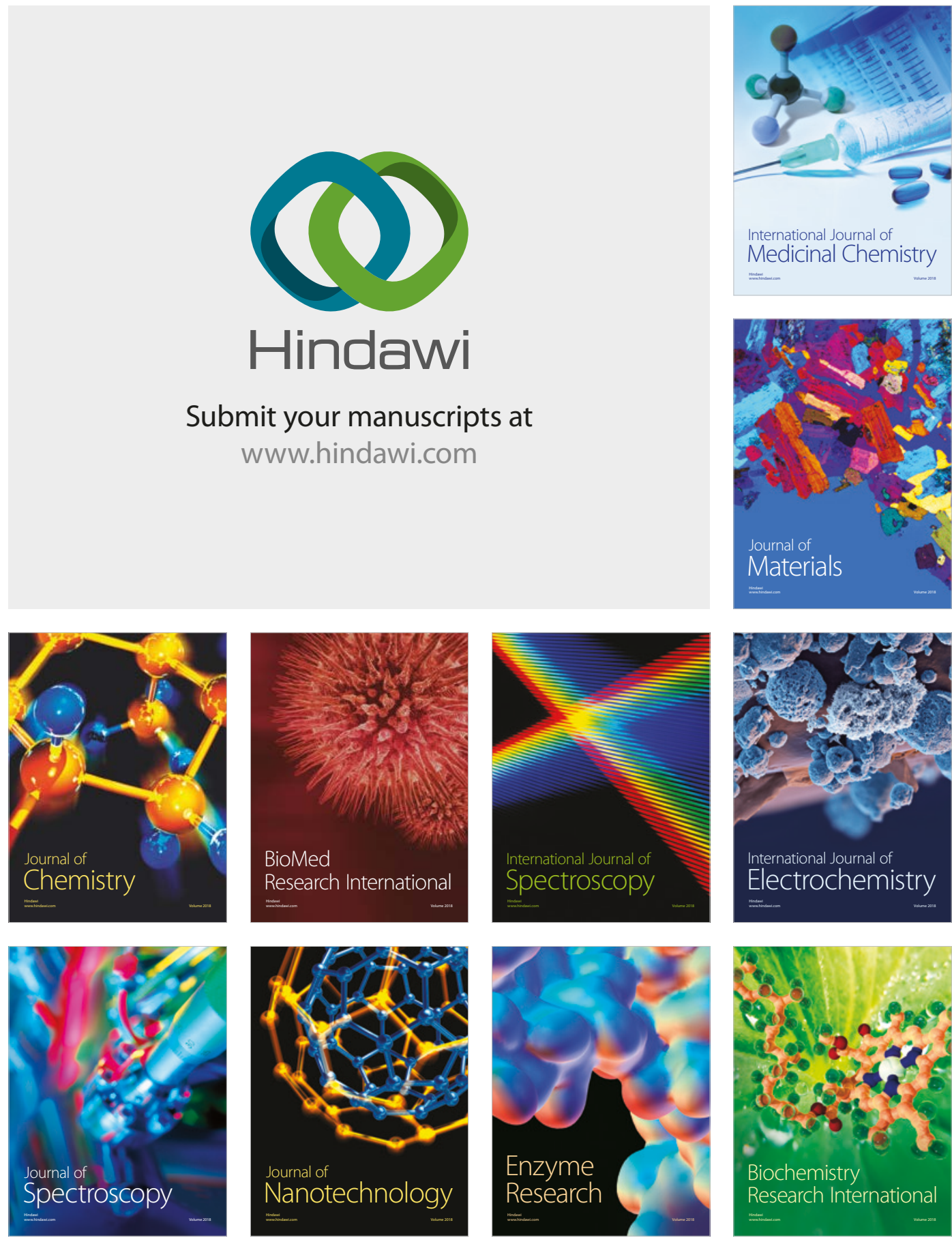
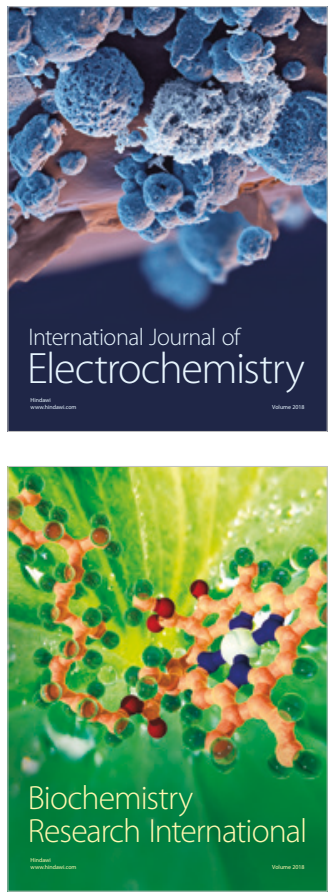